\title{
Association Between Type-specific HPV Infections and hTERT DNA Methylation in Patients with Invasive Cervical Cancer
}

\author{
MÓNICA MOLANO ${ }^{1,2,3}$, PABLO MORENO-ACOSTA $^{1,2}$, NICOLÁS MORALES $^{1}$, MARCELA BURGOS $^{1}$, \\ LINA BUITRAGO ${ }^{4}$, OSCAR GAMBOA ${ }^{2,4}$, RAYNER ALVAREZ ${ }^{1,2}$, SUZANNE M. GARLAND ${ }^{3,5,6}$, \\ SEPEHR N. TABRIZI ${ }^{3,5,6}$, RENSKE D.M. STEENBERGEN ${ }^{7}$ and JUAN CARLOS MEJÍA ${ }^{8}$
}

\author{
${ }^{1}$ Research Group in Cancer Biology, Research Branch, National Cancer Institute, Bogotá, Colombia; \\ ${ }^{2}$ Research Group in Radiobiology Clinical, Molecular and Cellular, National Cancer Institute, Bogotá, Colombia; \\ ${ }^{3}$ Microbiology and Infection Diseases, The Royal Women's Hospital, Melbourne, VIC, Australia; \\ ${ }^{4}$ Unit Group of Analysis, Research Branch, National Cancer Institute, Bogotá, Colombia; \\ ${ }^{5}$ Murdoch Children's Research Institute, Parkville, VIC, Australia; \\ ${ }^{6}$ Department of Obstetrics and Gynaecology, University of Melbourne, Parkville, VIC, Australia; \\ ${ }^{7}$ Department of Pathology, VU University Medical Center, Amsterdam, the Netherlands; \\ ${ }^{8}$ Oncological Pathology Group, National Cancer Institute, Bogotá, Colombia
}

\begin{abstract}
Background: There exists limited information on the role of hTERT methylation, and its association with type-specific HPV infections in cervical cancer. Materials and Methods: Eighty-seven frozen samples were analyzed for type-specific HPV infection using a $G P 5^{+} / G P 6^{+} P C R$ $R L B$ assay (RLB). hTERT DNA methylation analysis was performed using a newly developed PCR-RLB-hTERT. Results: Ninety-three percent of samples were HPV-positive and fifteen different types were detected. hTERT methylation analysis of region 1 revealed no methylation in $78.8 \%$ of the samples and partial methylation in $21.2 \%$. In region two, $68.2 \%$ showed no methylation and $31.8 \%$ showed a pattern of partial methylation. An association between the alpha 9 and alpha 7 species with a pattern of no methylation of hTERT in the region 1 was established ( $p=0.02$ and $p=0.03$, respectively). Conclusion: Differences in patterns of methylation of the hTERT core promoter [region 1 ( $n t-208$ to -1$)$ and region $2(n t+1$ to +104$)$ relative to first $A T G]$ are related to the HPV species present.
\end{abstract}

Cervical cancer remains one of the most common cancers in women worldwide. According to GLOBOCAN statistics on cervical cancer (1), there were approximately 528,000

Correspondence to: Dr. Pablo Moreno-Acosta, Ph.D, Research Group in Radiobiology Clinical, Molecular and Cellular, Research Group in Cancer Biology, National Cancer Institute, Bogotá, Colombia. Tel: +57 13103047985, e-mail: pmoreno@ cancer.gov.co

Key Words: DNA methylation, uterine cervical neoplasms, telomerase reverse transcriptase, papillomavirus infections. new cases and 266,000 deaths in 2012, of which more than $85 \%$ occurred in developing countries. Infections with high-risk human papillomavirus (hrHPV) types are detected in virtually all cervical carcinomas $(2,3)$. At least 13 genotypes of the alpha genus (HPV types 16, 18, 31, 33, $35,39,45,51,52,56,58,59$, and 68) have been associated with the risk to develop cervical cancer and are defined as "carcinogenic" viral types (4-6). HPV16 and 18 are the most prevalent genotypes found in squamous cell carcinoma across the world (7). However, in addition to an hrHPV infection, accumulating genetic and epigenetic alterations in the host cell genome is required for progression of hrHPV-induced precancerous lesions to invasive cancer. One crucial hallmark of invasive cancer is immortalization, characterized by an increased activity of telomerase (8).

Telomerase is a ribonucleoprotein enzyme complex that adds 5'-TTAGGG-3' repeats onto the ends of human chromosomes, providing a telomere maintenance mechanism in about $90 \%$ of cancers (8). Telomerase consists of several subunits including a catalytic subunit (hTERT) and a structural RNA component (TERC). The last component acts as a template for elongation of telomeric DNA (9). TERC has been shown to be widely expressed in most cell types, and even in telomerase-negative cells, such as differentiated somatic cells. The expression of TERT is tightly regulated during differentiation and is either not expressed or expressed at very low levels in most somatic cells. Expression of hTERT is restricted to telomerase-positive cells, indicating that hTERT expression controls telomerase activity (10). In addition, expression of hTERT along with activated oncogenes results in tumorigenesis $(11,12)$. 
Studies on the $h T E R T$ gene have shown that the promoter region contains a cytosine-guanine dinucleotide $(\mathrm{CpG})$ island (CGI) and its transcriptional regulation may involve DNA methylation (13). Reports studying the methylation status within this region have been contradictory (14-21). While some studies showed that methylation of the hTERT promoter was associated with gene silencing $(14,16,17)$, other studies showed no correlation between the methylation of the hTERT promoter and expression of the gene $(18,19)$. These different correlations between DNA methylation and TERT expression may result, in part, from the different regions analyzed, variability of methods used, type of samples studied and histological diagnosis (22). A few studies have also shown that DNA methylation plays a role in deregulated hTERT expression and is implicated in human papillomavirus (HPV)-mediated pathogenesis of cervical cancer. In 2010 de Wilde and collaborators, concluded that methylation of transcriptionally repressive sequences in the hTERT promoter and proximal exonic sequences is correlated to deregulated hTERT transcription in HPVimmortalized cells and cervical cancer cells. They proposed that detection of DNA methylation at these repressive regions can be used as an attractive biomarker for early detection of cervical cancer (10). Jiang et al. in 2012 showed that HPV16 E6 can promote TERT transcription through demethylating the DNA sequence around the TERT transcription start site. In addition, Schütze et al. in 2015 showed that E6/E7 of HPV16, 18, 31, 33, 45, 66, and 70 have differential capacities to immortalize primary keratinocytes and longitudinal analysis of these cells revealed that the onset of hTERT methylation during passaging was HPV type dependent (23-25). However, limited data exist on the pattern of hTERT methylation and its association with the presence of specific HPV types in clinical samples. The aim of this study was to analyze the patterns of methylation in the $h T E R T$ core promoter and to explore its possible association with HPV type-specific infections using clinical samples of patients with invasive cervical cancer.

\section{Materials and Methods}

Study population. Frozen tissue biopsies were obtained from the department of Gynaecology of the National Cancer Institute in Bogota, Colombia as part of the project "Loss of heterozygosity on chromosomes 6 and 15, expression of HLA-I, HLA-G and IL-10 in women with histologically confirmed diagnosis of cervical cancer. These included $81(93.1 \%)$ patients with squamous cell carcinoma and $6(6.9 \%)$ patients with adenocarcinoma. Participants of this study gave written consent for subsequent use of their samples in other research projects.

Bisulfite modification. Sodium bisulfite modification, which induces chemical conversion of unmethylated cytosines into uracils, whereas methylated cytosines are protected from this conversion, was

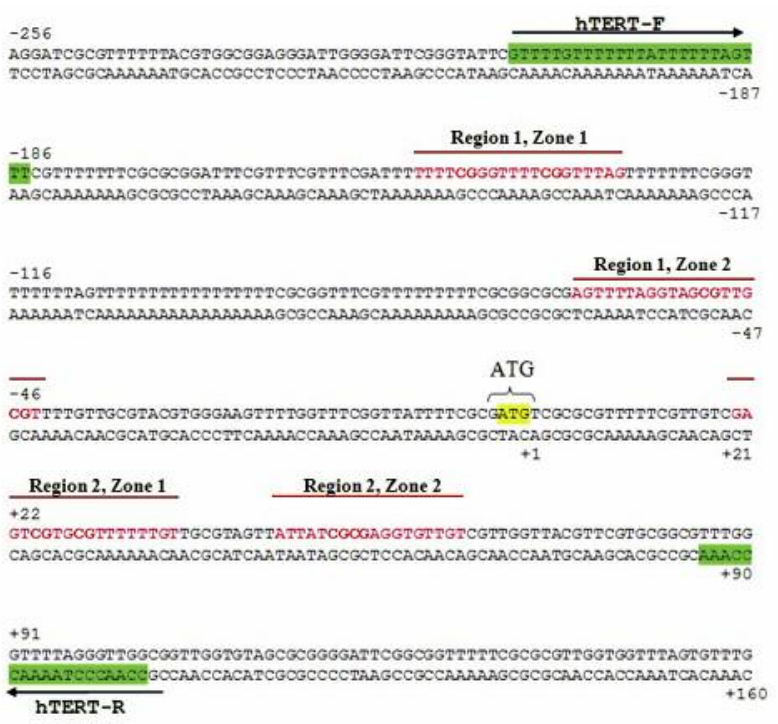

Figure 1. Schematic representation of the hTERT core promoter including regions, $C p G$ sites studied and location of PCR primers. hTERT-F and hTERT-R indicate the forward and reverse primers respectively. Region 1 ( $n t-208$ to -1$)$ and Region $2(n t+1$ to +104$)$ relative to first ATG. Red sequences indicate the localization of the probes designed and specific CpG sites studied. Region 1, zone 1 contain AP2 binding sites, Region 1, zone 2 contains c-Myc binding sites, Region 2, zone 1 and zone 2 contain CTCF binding sites.

performed using the EZ DNA Methylation Kit, according to the manufacturer's guidelines (Zymo Research, Orange, CA, USA).

PCR amplification and hTERT methylation using RLB. hTERT DNA methylation analysis was performed on bisulfite modified DNA using a new PCR-RLB-hTERT methylation assay targeting two regions flanking the hTERT core promoter [region 1 (nt -208 to -1 ) and region 2 (nt +1 to +104 ) relative to first ATG (Figure 1). In brief, the primers hTERT-F: 5' GTTTTGTTTTTTTATTTTT TAGTTT 3' and hTERT-R: biot 5' CCAACCCTAAAACCCAAA 3' were used to amplify a fragment of $312 \mathrm{bp}$ according to de Wilde et al. (10). Thermocycler conditions were as follows: denaturation for $4 \mathrm{~min}$ at $95^{\circ} \mathrm{C}$, followed by 40 cycles of amplification consisting of $60 \mathrm{sec}$ at $95^{\circ} \mathrm{C}, 60 \mathrm{sec}$ at $53^{\circ} \mathrm{C}$, and $60 \mathrm{sec}$ at $72^{\circ} \mathrm{C}$, with a final extension of $4 \mathrm{~min}$ at $72^{\circ} \mathrm{C}$. The amplification conditions, resulted in biotinylated hTERT-PCR products. To test for potential amplification bias, PCRs were performed on serial dilutions of methylated DNA in unmethylated DNA $(100 \%, 75 \%, 50 \%, 25 \%$, $10 \%$ and $0 \%$ ). Negative controls, with all of the reaction components but devoid of DNA, and human methylated and nonmethylated DNA controls (Zymo Research), were included in each experiment.

RLB analyses were performed as described elsewhere by Molano et al. (26). In brief, hTERT specific oligonucleotide probes containing a 5-amino group were covalently attached to a Biodyne C membrane (Pall BioSupport), in parallel lines, by use of a miniblotter. Four different pairs of oligonucleotide probes directed against the hTERT gene were used to identify 8 different 
Table I. Oligonucleotide probes directed against the hTERT gene.

\begin{tabular}{lcr}
\hline Probes & Sequence & Final concentration (pmol) \\
\hline hTERT-R1-Z1-A & 5'-TTTTCGGGTTTTCGGTTTAG-3' & 200 \\
hTERT-R1-Z1-B & 5'-TTTTTGGGTTTTTGGTTTAG-3' & 200 \\
hTERT-R1-Z2-A & 5'-AGTTTTAGGTAGCGTTGCGT-3' & 125 \\
hTERT-R1-Z2-B & 5'-AGTTTTAGGTAGTGTTGTGT-3' & 125 \\
hTERT-R2-Z1-A & 5'-GAGTCGTGCGTTTTTTGT-3' & 50 \\
hTERT-R2-Z1-B & 5'-GAGTTGTGTGTTTTTTGT-3' & 50 \\
hTERT-R2-Z2-A & 5'-ATTATCGCGAGGTGTTGT-3' & 300 \\
hTERT-R2-Z2-B & 5'-ATTATTGTGAGGTGTTGT-3' & 350 \\
\hline
\end{tabular}

hTERT probes with letter A show CG dinucleotides in red color allowing to establish if the DNA is methylated and hTERT probes with letter B show TG dinucleotides in red allowing establish if the DNA is unmethylated. Letter R, indicate region, letter $\mathrm{Z}$ indicate zone. [ ] Indicates concentration in picomoles.

Table II. Frequency of single and multiple HPV infections.

\begin{tabular}{lccc}
\hline Single Infections (73 samples) & HPV & $\mathrm{n}$ & $\%$ \\
\hline & 16 & 46 & 63.0 \\
& 18 & 5 & 6.8 \\
& 45 & 4 & 5.5 \\
& 52 & 4 & 5.5 \\
& 35 & 4 & 5.5 \\
& 56 & 2 & 2.7 \\
& 31 & 2 & 2.7 \\
Multiple Infections (8 samples) & 58 & 2 & 2.7 \\
& 59 & 2 & 2.7 \\
& 39 & 1 & 1.4 \\
& 66 & 1 & 1.4 \\
& $16,34,11$ & 1 & 12.5 \\
& 16,33 & 1 & 12.5 \\
& 16,59 & 1 & 12.5 \\
& 16,45 & 1 & 12.5 \\
& 16,56 & 1 & 12.5 \\
& 16,58 & 1 & 12.5 \\
& 45,56 & 1 & 12.5 \\
& 52,66 & 1 & 12.5 \\
\hline
\end{tabular}

CpG sites (Table I). After binding of the oligonucleotide probes, the membrane was removed from the miniblotter and rotated. The slots of the miniblotter that were perpendicular to the oligonucleotide-probe lines were filled with $10 \mathrm{ml}$ of each biotinylated hTERT-PCR product generated. Hybridization was performed in the miniblotter at $50^{\circ} \mathrm{C}$ with subsequent washing temperatures at $57^{\circ} \mathrm{C}$ and the reaction was visualized by use of peroxidase- labeled streptavidin, which interacted with the biotin of the probe, followed by enhanced chemiluminescense detection, as described in detail elsewhere (26).

$H P V$ detection. HPV-DNA detection was performed by a standard GP5+/GP6+ PCR-based assay, which allows for the detection of a broad spectrum of genital HPV types. Subsequently, a specific RLB assay was used to type 37 specific HPV types (14 high risk types and 23 low risk types) (27).
Statistical analysis. Description of the data was performed by using frequencies (percentages) for categorical variables. Fisher's exact Chi-square test was used to establish an association between hTERT methylation and HPV infection taking into account analysis of HPV species (alpha 7 and alpha 9). The R Statistical Software was used for all statistical analyses. A $p$-value of less than 0.05 was considered statistically significant.

\section{Results}

A total of 81/87 (93.1\%) samples were HPV-positive. Fifteen different types were detected. Of the HPV-DNA positive samples, $73(90.1 \%)$ had single HPV infections and $8(9.9 \%)$ had multiple HPV infections. In single infections, HPV 16 was the most frequently type found in $63 \%$ of the samples, followed by HPV18 (6.8\%) and HPV45 (5.5\%). In multiple infections, HPV 16 was also the most common type found in $62.5 \%$ of the samples, followed by HPV 56 and 45 (25\%) (Table II). Low-risk types were detected in multiple infections only. The RLB assay developed for hTERT methylation allowed for analysis of specific zones within the region 1 and region 2 of the hTERT core promoter with high sensitivity and specificity. With this technique, we were able to detect up to $5 \%$ of methylated DNA in a background of unmethylated DNA. hTERT methylation could be analysed in $85 / 87(97.7 \%)$ of cancer specimens. Figure 2 shows the various patterns of hTERT methylation in the two regions analyzed that were detected in the cancer specimens.

Analysis of region 1 revealed no methylation in $78.8 \%$ of the samples and partial methylation in $21.2 \%$ of the samples. In region two, $68.2 \%$ of the samples showed no methylation and $31.8 \%$ showed a pattern of partial methylation (Figure $3 \mathrm{~A})$. None of the samples analyzed showed $100 \%$ methylation within the two regions. Specific analysis by zones showed that zone 1 of region 1 (AP2 binding site) was unmethylated in $87.6 \%$ of the samples, and zone 1 of region 2 (CTCF binding site) showed partial methylation in $32.4 \%$ of the samples (Figure 3B). 
Table III. hTERT methylation by HPV type and species.

\begin{tabular}{|c|c|c|c|c|c|}
\hline \multirow[t]{2}{*}{ Specie } & \multirow[t]{2}{*}{$\begin{array}{l}\text { HPV } \\
\text { type }\end{array}$} & \multicolumn{2}{|c|}{$\begin{array}{c}\text { Region } 1 \\
\text { (nt }-208 \text { to }-1)\end{array}$} & \multicolumn{2}{|c|}{$\begin{array}{c}\text { Region } 2 \\
(\mathrm{nt}+1 \text { to }+104)\end{array}$} \\
\hline & & NM\% & PM\% & NM\% & PM\% \\
\hline \multirow[t]{5}{*}{ Specie alpha 9} & 16 & 75.5 & 24.5 & 66.7 & 33.3 \\
\hline & 52 & 75 & 25 & 75 & 25 \\
\hline & 35 & 75 & 25 & 75 & 25 \\
\hline & 31 & 0 & 100 & 0 & 100 \\
\hline & 58 & 100 & 0 & 100 & 0 \\
\hline \multirow{4}{*}{ Specie alpha 7} & 18 & 100 & 0 & 80 & 20 \\
\hline & 45 & 100 & 0 & 75 & 25 \\
\hline & 59 & 100 & 0 & 100 & 0 \\
\hline & 39 & 100 & 0 & 100 & 0 \\
\hline \multirow[t]{2}{*}{ Specie alpha 6} & 56 & 75 & 25 & 50 & 50 \\
\hline & 66 & 100 & 0 & 0 & 100 \\
\hline
\end{tabular}

NM, No methylation; PM, partial methylation.

Descriptive analysis of the relation between $h T E R T$ methylation and HPV infection taking into account HPV type and HPV species is shown in Table III.

All samples with HPV types belonging to the alpha 7 species (HPV 18, 45 and 59) were unmethylated in region 1 and only a minority (20-25\%) showed partial methylation in region 2. In contrast in samples with HPV types belonging to the alpha 9 species $(16,52,35,31$ and 58) partial methylation was detected in region 1 in $25-100 \%$ of the cases, except for HPV 58 positive cases. In region 2 partial methylation varied from $0 \%$ for HPV 58-positive samples to $100 \%$ for HPV 31 positive samples. Statistical analysis showed a significant association between alpha 9 and alpha 7 species with hTERT methylation status (no methylation) in region $1, p$-values 0.02 and 0.03 , respectively. However, HPV types of the alpha 9 species seem to have a higher probability to have a partial methylation in region 1 compared with HPV types that belong to other species (5.82 IC $0.82-41.54)$. An association of the methylation status between regions was also observed $(p=0.005)$.

Table IV summarized some of the most important studies on hTERT methylation that have been performed on the field including both basic and clinical studies.

\section{Discussion}

Recent investigations have indicated that methylation of the hTERT gene could be an attractive biomarker for early detection of cervical cancer and that the methylation pattern may be dependent on the HPV type $(23,25)$. Therefore, in this study, we analyzed the patterns of methylation in the $h T E R T$ core promoter and explored its possible association

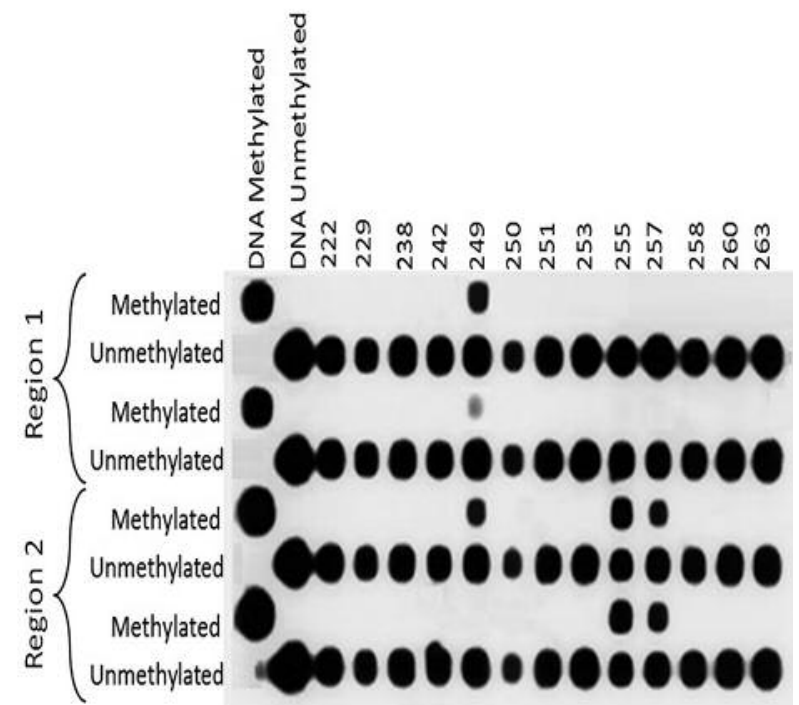

Figure 2. hTERT PCR/Reverse line blot methylation assay. Horizontal lines show the patterns of methylation by region and zones. Vertical lines 1 and 2 shows DNA Methylated and DNA unmethylated controls. Lines 3-15 show the patterns of methylation of different clinical samples. Partial methylation is detected when the DNA is joined to both: methylated and unmethylated probes (samples 249, 255 and 257).

with specific HPV infection using clinical samples of patients with invasive cervical cancer. Our study showed that the hTERT promoter region studied (nt $-208-+104)$ was not methylated in the majority of cervical cancer samples. This result is consistent with those reported by Jing Jiang and collaborators who found a low percentage of methylation analyzing cervical cancer cell lines (CaSki, SiHa and HeLa) (23). These results are also consistent with those reported by Zinn and collaborators indicating that telomerase-positive cell lines maintain alleles with low levels of methylation near the transcription start site despite being heavily methylated in upstream regions (21). Similarly, in a large panel of HPVE6E7-immortalized keratinocyte cell lines, the transcription core of hTERT and known repressor sites remained largely unmethylated (25). Our results support the statement that the core promoter needs to remain unmethylated to allow hTERT activation, which is consistent with the usual dogma of gene expression and epigenetic changes that states that the absence of DNA methylation around the transcription start site is required to enable the gene expression (23).

A more specific analysis by regions in our study showed that region 1 (nt -208 to -1 ) of the core promoter region showed a lower rate of methylation compared to downstream region 2 (nt $+1-+104)$ of the first exon. These results are similar to those recorded by Renaud and collaborators. They 
A

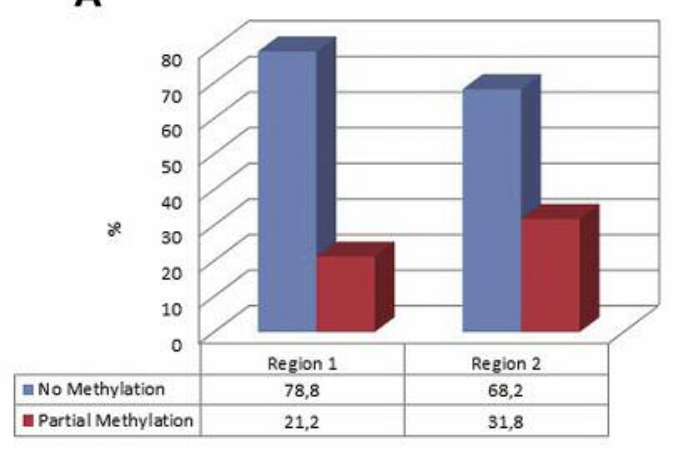

B

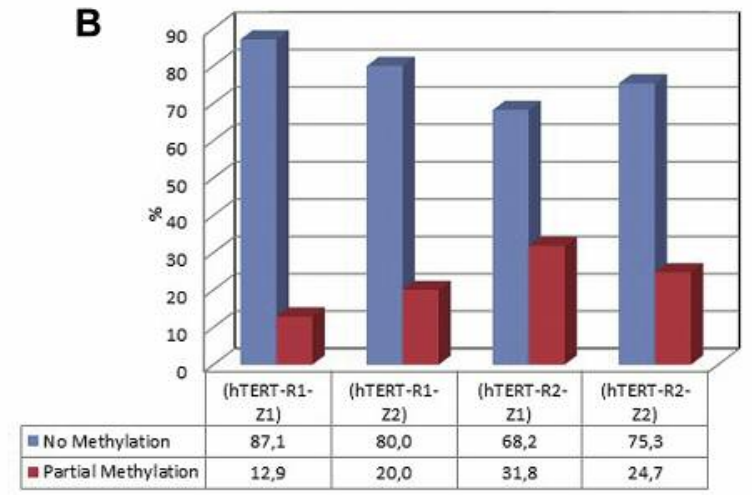

Figure 3. Methylation status of core promoter hTERT gene. (A) According to region: Blue bars indicate a pattern of no methylation (percentage) and red bars indicate a pattern of partial methylation (percentage) in the regions studied. (B) According to zone. Blue bars indicate a pattern of no methylation (percentage) and red bars indicate a pattern of partial methylation (percentage) in the zone studied.

proposed that $h T E R T$ promoter region is mostly unmethylated as it harbors binding sites for transcription factors that positively regulate $h T E R T$, while the region of the first exon shows increased methylation because it is target of a repressor protein (CTCF), indicating that this epigenetic mechanism acts as a barrier that prevents the binding of CTCF $(28,29)$. Our analysis by zones (specific transcription factor binding sites previously associated with hTERT regulation) confirmed these results, showing an unmethylated pattern at the AP2 binding site and E-Box (cmyc binding sites) and an increasing percentage of partial methylation at CTCF binding sites $(15,25)$. Although the percentage of partial methylation in region 2 was higher compared with region 1 , the unmethylated state was still the most common mechanism in this region. This can be associated with other regulatory mechanisms such as BORIS/ CTCFL protein in the first exon. This protein can inhibit the repressor favoring transcription. BORIS has been associated with hTERT as reported by Renaud et al. in 2011 analyzing ovarian tumor cells and testis (30).

Our results suggest an association between the high-risk HPV type present and the hTERT methylation status (no methylation) in region 1, which seems HPV species related. To the best of our knowledge, this is the first study that indicates differences on hTERT methylation associated with HPV species in clinical specimens. Some researchers using SiHa and HeLa cervical cell lines or HPV-immortalized keratinocyte cell lines have found differences on hTERT methylation according HPV type infection $(23,25)$. Analysis of similar region (nt $-156-+162 b p$ ) in cancer cell lines showed differences in percentages of methylation in HPV16 CaSki (60.3\%), HPV16 SiHa (44.8\%) and HPV18 Hela $(28.8 \%)$ cell lines with a hypomethylation pattern around the transcriptional start site of hTERT (23). In a study on HPVimmortalized keratinocytes, differences in hTERT methylation in the region $\mathrm{nt}+288-+419$ were seen between in HPV45-, 66-, and 70-immortalized cells that underwent a crisis period prior to immortalization compared to HPV16-, 18-, 31-, and 33-immortalized cells that grew continuously (25). In our study, cancers infected with HPV types that belong to alpha 9 species seem to have a higher probability to have a partial methylation in region 1 compared to cancers associated with HPV types that belong to other species. Furthermore, our results showed that in the presence of HPV types that belong to the alpha 7 species, no methylation was detected in region 1 . These results indicate that differences in patterns of hTERT methylation in cervical cancers are associated with HPV species and specific HPV type. Some studies have found that the HPV-encoded E6 protein plays a prominent role in hTERT gene activation by binding to cMyc or E6AP $(31,32)$ and that E6 proteins of different HPVtypes have different capacities to transactivate hTERT (33). Additionally, other research found that HPV16 E6 can promote TERT transcription through demethylating the DNA sequence around the TERT transcription start site but HPV 18 E6 could not affect DNA methylation of the TERT promoter in HeLa cells (23). In addition to the different E6 activation capacities of types and probably of the HPV species and the site-dependent methylation patterns, the involvement of a large variety of transcription factors interacting with the TERT promoter may also contribute to hTERT gene activation $(15,32)$.

hTERT methylation and hTERT expression are rarely seen in early lesions and they seem to be a late event in cervical carcinogenesis associated with progression to CIN3+ (34-37). Differences in hTERT methylation and hTERT expression between normal or early lesions compared to advanced lesions indicate that hTERT is a promising marker in the identification of CIN3+ lesions. Branca et al. who studied hTERT expression in a large series on CIN and CC lesions, showed an increased 
Table IV. Basic and clinical studies on hTERT methylation.

\begin{tabular}{lccc}
\hline $\begin{array}{l}\text { Author } \\
\text { Year -Refrence }\end{array}$ & $\begin{array}{c}\text { Type of } \\
\text { sample }\end{array}$ & $\begin{array}{c}\text { hTERT } \\
\text { promoter (nt) }\end{array}$ & Method of Analysis \\
\hline $\begin{array}{l}\text { de Wilde J } \text { et al. } \\
(2010)(10)\end{array}$ & $\begin{array}{c}\text { HPV16- and } \\
\text { HPV18-immortalized } \\
\text { keratinocyte cell lines, } \\
\text { cervical cancer cell lines } \\
\text { and cervical specimens }\end{array}$ & -442 to & $\begin{array}{c}\text { Bisulfite-modified DNA, } \\
\text { sequencing analysis and } \\
\text { quantitative methylation } \\
\text { specific PCR (qMSP) analysis }\end{array}$ \\
& & &
\end{tabular}

Shin KH et al. (2003) (14)

Lopatina NG et al. (2003) (16)

Liu L et al. (2004) (17)

\section{Devereux TR}

et al. (1999)

(18)

Dessain SK et al. (2000) (19)

Guilleret I et al. (2002) (20)

Zinn RL et al. (2007) (21)

Jiang $\mathrm{J}$ et al (2012) (23)
Normal human oral fibroblast (NHOF), normal human oral keratinocytes (NHOK) and SCC-4 (human squamous cell carcinoma cell line)

Colorectal carcinomas tissues, colon normal tissues and HCT 116 colon cancer

\section{-442 to} $+170$

Bisulphite-modified DNA and sequencing

665 to Bisulphite-modified DNA,

$+5$ and methylation-specific PCR

$$
\text { DNA and sequencing }
$$

Bisulphite-modified DNA and sequencing

$\begin{array}{lr}\text { human teratocarcinoma } & -577 \text { to }\end{array}$

$$
\text { (HT) cells }
$$

Human teratocarcinoma (HT) cells and human acute myeloid leukemia (HL60) cells.

Normal, immortalized, and cancer cell lines from lung, breast, and other tissues

normal, immortalized, and cancer cell lines

-385 to

Bisulphite-modified DNA, and methylation-specific PCR

Bisulphite-modified DNA and sequencing

Bisulphite-modified DNA and sequencing

56 human tumor cell lines, as well as tumor and normal tissues from different organs

Methylation-sensitive single-strand conformation analysis (MS-SSCA), bisulfite-modified DNA and direct sequencing

Colon, breast, leukemia and lung $\quad-650$ to cancer cell lines, immortalized cell lines, and normal cells
Bisulphite-modified DNA, sequencing analysis and methylation-specific PCR
Cervical cell lines $\quad-624$ to

(SiHa, CaSki and HeLa)
Relevant results or methyltion status

Increased methylation in

hTERT positive cells compared to cells with no or low hTERT expression. qMSP on cervical tissue showed methylation in $100 \%$ of cervical carcinomas, in $39 \%$ of HSIL, $9 \%$ of LSIL and $5 \%$ of normal controls.

Hypermethylation of the hTERT promoter inhibited the expression of telomerase activity in NHOF and NHOK.

hTERT expression induced when $\mathrm{P} 1$ and $\mathrm{P} 2$ region of hTERT were hypermethylated and region G1 hypomethylated. Three CpG differently methylated in colorectal carcinoma and normal tissues.

HT cell expreseds high levels of hTERT and the hTERT promoter was unmethylated.

During differentiation a gradual accumulation of methylated cytosines in the hTERT promoter. It was less methylated in pluripotent HT cells that in multipotent HL60 cells.

There was not a generalized pattern of site-specific or region-specific methylation that correlated with expression of the $h T E R T$ gene.

hTERT CpG island can undergo cytosine methylation in cultured cells and tumors and DNA methylation may contribute to the regulation of the hTERT gene.

Direct correlation between methylation of the hTERT promoter and hTERT gene expression and telomerase activity.

All cancer cell lines were little or no methylated around the transcription start site but were densely methylated in a region $600 \mathrm{bp}$ upstream of the transcription start site.

Bisulphite-modified DNA sequencing analysis and methylation-specific PCR
Hypomethylation around the transcription start site $(-156$ to +162$)$ enables the expression of TERT. 
Table IV. Continued

\begin{tabular}{|c|c|}
\hline $\begin{array}{l}\text { Author } \\
\text { Year-Refrence }\end{array}$ & $\begin{array}{l}\text { Type of } \\
\text { sample }\end{array}$ \\
\hline $\begin{array}{l}\text { Schütze DM et al. } \\
(2015)(25)\end{array}$ & $\begin{array}{l}\text { HPV immortalized } \\
\text { keratinocyte cell lines, cervical } \\
\text { cancer cell lines ( } \mathrm{SiHa}, \mathrm{CaSki}) \text {, } \\
\text { lung cancer cell line (A549) }\end{array}$ \\
\hline $\begin{array}{l}\text { Renaud S et al. } \\
(2007)(29)\end{array}$ & $\begin{array}{l}\text { Cell lines HeLa, SW480, normal } \\
\text { BJ fibroblasts and breast, } \\
\text { bladder and cervix tumor tissues }\end{array}$ \\
\hline $\begin{array}{l}\text { Eijsink JJ et al. } \\
(2012)(35)\end{array}$ & $\begin{array}{c}\text { Frozen tissue samples from } \\
84 \text { cervical cancer patients and } \\
106 \text { normal cervices. Cervical } \\
\text { scrapes: } 74 \text { cancers and } 69 \text { normal } \\
\text { scrapes. Validation as a diagnostic } \\
\text { marker in } 148 \text { scrapes from } \\
\text { patients with abnormal Pap smear }\end{array}$ \\
\hline
\end{tabular}

\begin{tabular}{|c|}
\hline $\begin{array}{l}\text { hTERT } \\
\text { moter (nt) }\end{array}$ \\
\hline
\end{tabular}

$\begin{array}{cc}\begin{array}{c}-442 \text { to } \\ +566\end{array} & \begin{array}{c}\text { Bisulfite-modified DNA, } \\ \text { sequencing analysis and } \\ \text { quantitative methylation } \\ \text { specific PCR (qMSP) analysis }\end{array} \\ -200 \text { to } & \begin{array}{c}\text { Bisulfite modification, PCR } \\ +100\end{array}\end{array}$
The onset of hTERT methylation during passaging was HPV type dependent.

hTERT methylation prevents binding of the CTCF repressor, but partial hypomethylation of the core promoter is necessary for hTERT expression.

Bisulfite modification, highthroughput quantitative methylation-specific PCRs (QMSP) on a novel OpenArray ${ }^{\mathrm{TM}}$ platform and quantitative methylation specific PCR (qMSP)

patients with abnormal Pap smear

Vasiljević $\mathrm{N}$ et al. (2014) (36)

Gasperov MN et al. (2015) (37)

Iliopoulos D et al. (2009) (38)

Boers A et al. (2016) (40)

215 cervical scrapes from patients with CINO, CIN1, CIN2, CIN3, and cancer

hTERT1 Bisulphite-modified DNA, (40 with normal cytology, (Chromosome 5: and methylation-specific 40 with LSIL/CIN1, 1295019- PCR 40 with HSIL/CIN2, 42 with HSIL/CIN3 and 11 with cervical cancer) 1295259), hTERT2

(Chromosome 5: 12948241295014)
115 cervical normal, ASCUS, LSIL, HSIL and cancer specimens
Bisulphite-modified DNA and real-time MethyLight analysis

Bisulfite modification and quantitative methylation specific PCR (qMSP)
Four methylation markers

(JAM 3, EPB41L3, TERT,

C13ORF18) were identified.

The methylation panel identified $94 \%$ of the cervical cancers and $83 \%$ and $21 \%$ of the CIN 3 and CIN1 cases. High risk HPV testing combined with the methylation panel improved the detection of

CIN 3 and cancer cases.

26 genes were analysed in a pilot study and TERT showed elevated methylation in CIN 3 compared with normal samples $p=0.0233$. However after correction for multiple comparisons, only EPB41L3 and EDNRB remained significant and they were tested in two large cohorts. specimens, including
9 genes were analysed and hTERT1 and hTERT2 showed high methylation levels in cancer samples compared with normal samples.

\footnotetext{
3 genes were analysed (hTERT, DAPK and MGMT). hTERT promoter hypermethylation was able to distinguish normal from cancer $(p=0.008)$, normal from premalignant $(p=0.036)$, as well as premalignant from cervical cancer cases $(p=0.003)$.

Four methylation markers (JAM 3, EPB41L3, TERT, C13ORF18) plus 8 new methylation markers were analysed. C13ORF18/ JAM3/ANKRD18CP showed the highest sensitivity and specificity to identify CIN2+ cases.
} 
expression of hTERT with the grade of cervical intraepithelial neoplasia with major up-regulation upon transition to CIN3. hTERT expression was $81 \%$ specific indicator of CIN3, with 95.3\% of positive predictive value (PPV), a sensitivity of $80.9 \%$ and negative predictive value (NPV) of $48.2 \%$. When they analyzed hTERT expression in the detection of CIN lesions, the specificity improved to $90 \%$ with a $98.7 \%$ PPV but the sensitivity dropped to $57.5 \%$ and NPV to $14.3 \%$. They proposed that a combination of the hTERT assay (showing high SP and PPV) with another test showing high SE and high NPV (as the HPV testing), could be an ideal screening tool for detection of CIN lesions (34). Recently, analyses of hTERT methylation or hTERT expression in combination with other biomarkers have been developed to improve the specificity in the detection of HSIL showing favourable results $(35,38-40)$. Future clinical studies should evaluate the use of hTERT methylation in combination with HPV species or HPV specific types, which could improve the detection of HSIL lesions.

\section{Conclusion}

Our results showed that differences in the methylation patterns of $h T E R T$ in clinical specimens of cervical cancers are associated with HPV type. Furthermore, the knowledge transmitted in this study could lead to new directions in understanding the development and progression of cervical cancer and could contribute to appropriate management through identification of molecular markers in detecting cervical intraepithelial neoplasia.

\section{Conflicts of Interest}

The Authors have no competing financial interests in relation to the work described.

\section{Acknowledgements}

The Authors thank Josefa Rodriguez for the partial collection and storage of the samples.

\section{References}

1 Ferlay J, Soerjomataram I, Dikshit R, Eser S, Mathers C, Rebelo M, Parkin DM, Forman D and Bray Fl: Cancer incidence and mortality worldwide sources, methods and major patterns in GLOBOCAN 2012. Int J Cancer 136: E359-E386, 2015.

2 Walboomers JM, Jacobs MV, Manos MM, Bosch FX, Kummer JA, Shah KV, Snijders PJ, Peto J, Meijer CJ and Muñoz N: Human papillomavirus is a necessary cause of invasive cervical cancer worldwide. J Pathol 189: 12-9, 1999.

3 Munoz N: Human papillomavirus and cancer: the epidemiological evidence. J Clin Virol 19: 1-5, 2000.

4 Munoz N, Bosch FX, de Sanjosé S, Herrero R, Castellsagué X, Shah KV, Snijders PJ, Meijer CJ and International Agency for Research on Cancer Multicenter Cervical Cancer Study Group:
Epidemiologic classification of human papillomavirus types associated with cervical cancer. N Engl J Med 348: 518-527, 2003.

5 Munoz N, Castellsague X, de Gonzalez AB, and Gissmann L: Chapter 1: HPV in the etiology of human cancer. Vaccine 24(3): S1-S10, 2006.

6 Bouvard V, Baan R, Straif K, Grosse Y, Secretan B, El Ghissassi F, Benbrahim-Tallaa L, Guha N, Freeman C, Galichet L, Cogliano $\mathrm{V}$ and WHO International Agency for Research on Cancer Monograph Working Group: A review of human carcinogens--part B: biological agents. Lancet Oncol 10: 321-322, 2009.

7 Li N, Franceschi S, Howell-Jones R, Snijders PJF and Clifford GM: Human papillomavirus type distribution in 30,848 invasive cervical cancers worldwide: variation by geographical region, histological type and year of publication. Int J Cancer 128: 927935, 2011.

8 Cohen SB, Graham ME, Lovrecz GO, Bache N, Robinson PJ and Reddel RR: Protein composition of catalytically active human telomerase from immortal cells. Science 315: 1850- 1853, 2007.

9 Feng J, Funk WD, Wang SS, Weinrich SL, Avilion AA, Chiu CP, Adams RR, Chang E, Allsopp RC and Yu J: The RNA component of human telomerase. Science 269: 1236-1241, 1995.

10 de Wilde J, Kooter JM, Overmeer RM, Claassen-Kramer D, Meijer CJ, Snijders PJ and Steenbergen RDM: hTERT promoter activity and $\mathrm{CpG}$ methylation in HPV-induced carcinogenesis. BMC Cancer 10: 271, 2010.

11 Hahn WC, Counter CM, Lundberg AS, Beijersbergen RL, Brooks MW and Weinberg RA: Creation of human tumour cells with defined genetic elements. Nature 400: 464-468, 1999.

12 Qi DL, Ohhira T, Fujisaki C, Inoue T, Ohta T, Osaki M, Ohshiro E, Seko T, Aoki S, Oshimura M and Kugoh H: Identification of PITX1 as a TERT suppressor gene located on human chromosome 5. Mol Cell Biol 31: 1624-1636, 2011.

13 Horikawa I, Cable PL, Afshari C and Barrett JC: Cloning and characterization of the promoter Region of human telomerase reverse transcriptase gene. Cancer Res 59(4): 826-830, 1999.

14 Shin KH, Kang MK, Dicterow E and Park NH: Hypermethylation of the hTERT promoter inhibits the expression of telomerase activity in normal oral fibroblasts and senescent normal oral keratinocytes. Br J Cancer 89(8): 1473-1478, 2003.

15 Choi JH, Park SH, Park J, Park BG, Cha SJ, Kong KH, Lee KH and Park AJ: Site specific methylation of $\mathrm{CpG}$ nucleotides in the hTERT promoter region can control the expression of hTERT during malignant progression of colorectal carcinoma. Biochem Biophys Res Commun 361: 615-620, 2007.

16 Lopatina NG, Poole JC, Saldanha SN, Hansen NJ, Key JS, Pita MA, Andrews LG and Tollefsbol TO: Control mechanisms in the regulation of telomerase reverse transcriptase expression in differentiating human teratocarcinoma cells. Biochem Biophys Res Commun 306(3): 650-659, 2003.

17 Liu L, Saldanha SN, Pate MS, Andrew LG and Tollefsbol TO: Epigenetic regulation of human telomerase reverse transcriptase promoter activity during cellular differentiation. Genes Chromosomes Cancer 41(1): 26-37, 2004.

18 Devereux TR, Horikawa I, Anna CH, Annab LA, Afshari CA and Barrett JC: DNA methylation analysis of the promoter region of the human telomerase reverse transcriptase (hTERT) gene. Cancer Res 59(24): 6087-6090, 1999.

19 Dessain SK, Yu H, Reddel RR, Beijersbergen RL and Weinberg RA: Methylation of the human telomerase gene $\mathrm{CpG}$ island. Cancer Res 60(3): 537-541, 2000. 
20 Guilleret I, Yan P, Grange F, Braunschweig R, Bosman FT and Benhattar J: Hypermethylation of the human telomerase catalytic subunit (hTERT) gene correlates with telomerase activity. Int $\mathrm{J}$ Cancer 101(4): 335-341, 2002.

21 Zinn RL, Pruitt K, Eguchi S, Baylin S and Herman JG: TERT is expressed in cancer cell lines despite promoter DNA methylation by preservation of unmethylated DNA and active chromatin around the transcription start site. Cancer Res 67(1): 194-201, 2007.

22 Gao W, Shi Y, Liu W, Lin WY, Wu JC, Chan JY and Wong TS: Diagnostic Value of Methylated Human Telomerase Reverse Transcriptase in Human Cancers: A Meta-Analysis. Front Oncol 5: 296, 2015.

23 Jiang J, Zhao LJ, Zhao C, Zhang G, Zhao Y, Li JR, Li XP and Wei LH: Hypomethylated $\mathrm{CpG}$ around the transcription start site enables TERT expression and HPV16 E6 regulates TERT methylation in cervical cancer cells. Gynecol Oncol 124: 534 $541,2012$.

24 Schutze DM, Snijders PJ, Bosch L, Kramer D, Meijer CJ and Steenbergen RD: Differential In Vitro Immortalization Capacity of Eleven (Probably) High-risk Human Papillomavirus Types. J Virol 88: 1714-1724, 2013.

25 Schütze DM, Kooter JM, Wilting SM, Meijer CJ, Quint W, Snijders PJ and Steenbergen RD:Longitudinal assessment of DNA methylation changes during HPVE6E7-induced immortalization of primary keratinocytes. Epigenetics 10: 73-81, 2015.

26 Molano M, Meijer CJ, Morré SA, Pol R and van den Brule AJ: Combination of PCR targeting the VD2 of omp1 and reverse line blot analysis for typing of urogenital Chlamydia trachomatis serovars in cervical scrape specimens. J Clin Microbiol 42: 2935-2939, 2004.

27 van den Brule AJC, Pol N, Fransen-Daalmeijer LM, Schouls C, Meijer CJ L M, and Snijders PJ: GP5+/6+ PCR followed by reverse line blot analysis enables rapid and high throughput identification of HPV genotypes, suitable for mass screening. J. Clin. Microbiol 40: 770-787, 2002.

28 Renaud S, Loukinov D, Bosman FT, Lobanenkov V and Benhattar J: CTCF binds the proximal exonic region of hTERT and inhibits its transcription. Nucleic Acids Res 33: 6850-6860, 2005.

29 Renaud S, Loukinov D, Abdullaev Z, Guilleret I, Bosman FT, Lobanenkov V and Benhattar J: Dual role of DNA methylation inside and outside of CTCF-binding regions in the transcriptional regulation of the telomerase hTERT gene. Nucleic Acids Res 35: 1245-1256, 2007.

30 Renaud S, Loukinov D, Alberti L, Vostrov A, Kwon YW, Bosman FT, Lobanenkov V, and Benhattar J: BORIS/CTCFLmediated transcriptional regulation of the hTERT telomerase gene in testicular and ovarian tumor cells. Nucleic Acids Res 39: 862-8673, 2011

31 Oh ST, Kyo S and Laimins LA: Telomerase activation by human papillomavirus type 16 E6 protein: induction of human telomerase reverse transcriptase expression through Myc and GC-rich Sp1 binding sites. J Virol 75: 5559-5566, 2001.
32 Veldman $T$, Liu $X$, Yuan $H$ and Schlegel R: Human papillomavirus E6 and Myc proteins associate in vivo and bind to and cooperatively activate the telomerase reverse transcriptase promoter. Proc Natl Acad Sci USA 100: 8211-8216, 2003.

33 Van Doorslaer K and Burk RD: Association between hTERT activation by HPV E6 proteins and oncogenic risk. Virology 433: 216-219, 2012.

34 Branca M, Giorgi C, Ciotti M, Santini D, Di Bonito L, Costa S, Benedetto A, Bonifacio D, Di Bonito P, Paba P, Accardi L, Mariani L, Ruutu M, Syrjänen S, Favalli $C$ and Syrjänen K: Upregulation of telomerase (hTERT) is related to the grade of cervical intraepithelial neoplasia but is not an independent predictor of high-risk human papillomavirus, virus persistence, or disease outcome in cervical cancer. Diagn Cytopathol 34(11): 739-734, 2006.

35 Eijsink JJ, Lendvai Á, Deregowski V, Klip HG, Verpooten G, Dehaspe L, de Bock GH, Hollema H, van Criekinge W, Schuuring E, van der Zee AG and Wisman GB: A four-gene methylation marker panel as triage test in high-risk human papillomavirus positive patients. Int J Cancer 130(8): 1861-1869. 2012.

36 Vasiljević N, Scibior-Bentkowska D, Brentnall AR, Cuzick J and Lorincz AT: Credentialing of DNA methylation assays for human genes as diagnostic biomarkers of cervical intraepithelial neoplasia in high-risk HPV positive women. Gynecol Oncol 132(3): 709-714, 2014.

37 Gašperov MN, Sabol I, Planinić P, Grubišić G, Fistonić I, Ćorušić A and Magdelena G: Methylated host cell gen promoters and human papillomavirus type 16 and 18 predicting cervical lesions and cancer. PLoS One 10(6): e0129452, 2015.

38 Iliopoulos D, Oikonomou P, Messinis I and Tsezou A: Correlation of promoter hypermethyltion in hTERT, DAPK and MGTM genes with cervical oncogenesis progression. Oncol Rep 22(1): 199-204, 2009.

39 Wang HY, Park S, Kim S, Lee D, Kim G, Kim Y, Park KH and Lee H: Use of hTERT and HPV E6/E7 mRNA RT-qPCR TaqMan assays in combination for diagnosing high-grade cervical lesions and malignant tumors. Am J Clin Pathol 143(3): 344-351, 2015.

40 Boers A, Wang R, van Leeuwen RW, Klip HG, de Bock GH, Hollema H, van Criekinge W, de Meyer T, Denil S, van der Zee AG, Schuuring E and Wisman GB: Discovery of new methylation markers to improve screening for cervical intraepithelial neoplasia grade 2/3. Clin Epigenetic 8: 29, 2016.
Received August 7, 2016

Revised September 11, 2016

Accepted September 21, 2016 